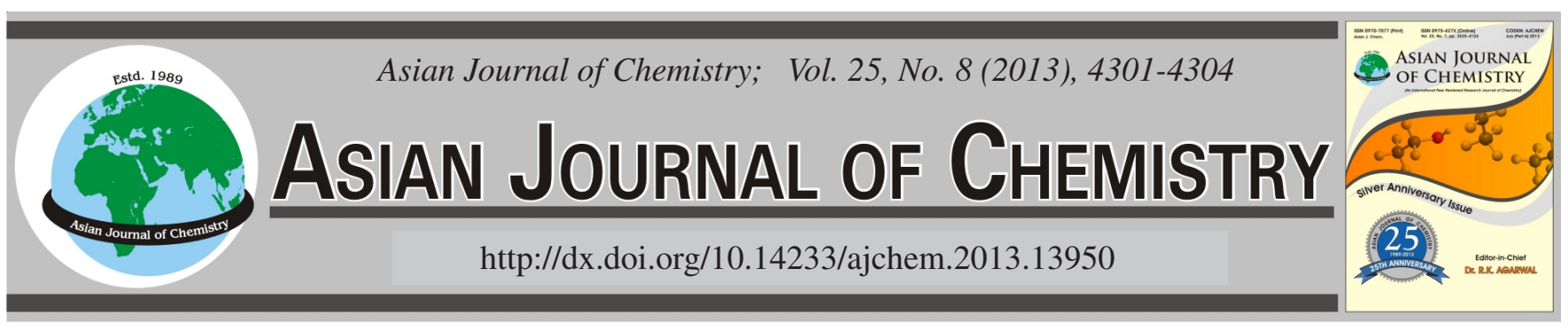

\title{
A Rapid Assay of Mezlocillin Sodium by Flow-Injection Chemiluminescence Detection
}

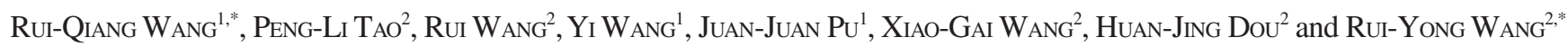

${ }^{1}$ First Affiliated Hospital of Zhengzhou University, Zhengzhou 450052, P.R. China

${ }^{2}$ Department of Chemistry, Zhengzhou University, Zhengzhou 450001, P.R. China

*Corresponding authors: E-mail: wangruiqiang@zzu.edu.cn; wangry@zzu.edu.cn

(Received: 24 April 2012;

Accepted: 9 February 2013)

AJC-12949

\begin{abstract}
A new chemiluminescence method coupled with the flow injection technique for the determination of mezlocillin sodium was developed. It was based on the enhancement of mezlocillin sodium on the chemiluminescence reaction of luminol with potassium ferricyanide in alkaline medium. Under the optimum conditions, the linear range for mezlocillin sodium was from $2.0 \times 10^{-7}$ to $5.0 \times 10^{-5} \mathrm{~g} \mathrm{~mL}^{-1}$ and the limit of detection was $6.8 \times 10^{-9} \mathrm{~g} \mathrm{~mL}^{-1}$. The relative standard deviation $(\mathrm{n}=11)$ was $0.31 \%$ for $8.0 \times 10^{-6} \mathrm{~g} \mathrm{~mL}^{-1} \mathrm{mezlocillin}$ sodium. The proposed method was applied successfully to the determination of mezlocillin sodium for injection with satisfactory results.

Key Words: Chemiluminescence, Flow-injection, Ceftezole sodium, Luminol.
\end{abstract}

\section{INTRODUCTION}

Mezlocillin sodium (Fig. 1) is a broad-spectrum penicillin antibiotic. It is active against both Gram-negative and some Gram-positive bacteria. Mezlocillin kills certain bacteria that cause infection, or stops their growth. It treats many kinds of infections including those of the skin, blood, central nervous system, respiratory tract, sinuses and urinary tract. It also treats certain infections in women (gynecological infections) ${ }^{1-7}$.

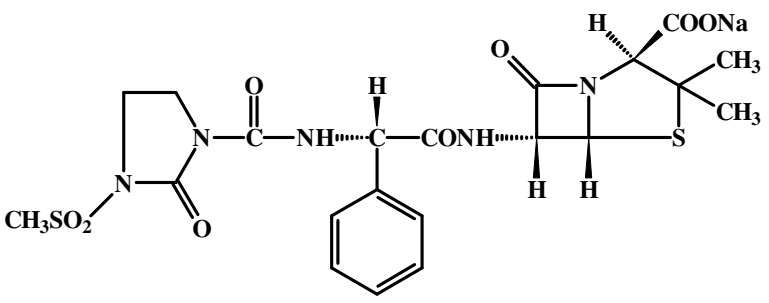

Fig. 1. Molecular structure of mezlocillin sodium

High-performance liquid chromatographic (HPLC) methods have been developed for the determination of mezlocillin. A number of papers on HPLC of mezlocillin describe the determination of these antibiotics in biological samples ${ }^{8-11}$. The reversed-phase mode is most commonly used, with precipitation, ultrafiltration and extraction of serum proteins prior to injection. Ultraviolet detection methods at around $220 \mathrm{~nm}$, which lack both sensitivity and selectivity have been mainly used for the assay of these penicillins. In order to enhance detectability, precolumn derivatization procedures have been investigated ${ }^{12-16}$.
Among these reports, most were costly, time consuming and use of volatile organic solvents. Thus, establishment of a simple, rapid and sensitive analytical method was very necessary.

Chemiluminescence methods provide many advantages for pharmaceutical determinations such as high sensitivity, small amount of chemical consumption, simple sample preparation and instrumentation ${ }^{17-21}$. When coupled with flow injection analysis, the flow-injection analysis-chemiluminescence (FIA-CL) methods provide low cost, rapid, simple and reproducible means and therefore, have attracted increasing attention and been successfully applied to drugs detection ${ }^{22-25}$. The aim of the present study is to use a new flow-injection analysis system with chemiluminescent detection for determination of mezlocillin sodium.

In this paper, the chemilumionescent behaviour of mezlocillin sodium in luminal-ferricyanide potassium media has been investigated for the first time. It is discovered that the chemiluminescence intensity increases significantly when the mezlocillin sodium solution is injected into the mixture of potassium ferricyanide and alkaline luminol. A simple and rapid flow injection chemiluminescence assay for mezlocillin sodium is developed and applied to the determination of mezlocillin sodium in samples with satisfactory results.

\section{EXPERIMENTAL}

IFFM-E Flow injection chemiluminescence analyze (Xi'an Remex Analyse Instrument Co. Ltd., Xi' an, China); IFFS-A multifunctional chemiluminescent detector (Xi'an Remex Analyse Instrument Co. Ltd, Xi' an, China); SYZ-A high-pure 
quartz sub-boiling stills (Jiang Su, New Diligence China Quartz Glass Instrument Factory, Yi Xing).

All the reagents were of analytical-reagent grade unless specified otherwise. Doubly distilled water was used during the whole experiment process. Mezlocillin sodium (HeNan Drug Examination Institute, China). Mezlocillin sodium for injection (ShanXi Qian-yuan Pharmaceuticals Co. Ltd., Shan $\mathrm{Xi}$, China). Stock solutions of mezlocillin sodium $\left(1.0 \times 10^{-4}\right.$ $\mathrm{g} \mathrm{mL}^{-1}$ ) were prepared and stored in the refrigerator at $4{ }^{\circ} \mathrm{C}$. Working standard solutions were prepared from the stock solution by appropriate dilution with water before use. Luminol (Sigma company, America) stock solutions $\left(1.0 \times 10^{-3} \mathrm{~mol} \mathrm{~L}^{-1}\right)$ were prepared by dissolving approximately $0.0177 \mathrm{~g}$ luminol with $0.1 \mathrm{~mol} \mathrm{~L}^{-1}$ sodium hydroxide solution and diluted to $100 \mathrm{~mL}$ with same sodium hydroxide solution in an ambercoloured measuring flask. Sodium hydroxide solution $(0.10$ mol L ${ }^{-1}$ ) was prepared daily, by dissolving $2 \mathrm{~g}$ sodium hydroxide (Tian Jin Heng Xing Chemical Reagent Co. Ltd., Tian Jin, China) with water and diluted to $500 \mathrm{~mL}$ with water. Stock solution of potassium ferricyanide $\left(3.0 \times 10^{-3} \mathrm{~mol} \mathrm{~L}^{-1}\right)$ was prepared by dissolving $0.0988 \mathrm{~g}$ potassium ferricyanide (Austria Sheng Tian Jin Chemical Reagent Co. Ltd., Tian Jin, China) with water and diluted to $250 \mathrm{~mL}$ in an amber-coloured measuring flask.

The schematic diagram of the flow injection system employed in this paper was shown in Fig. 2, which included two peristaltic pumps $\mathrm{P} 1$ and $\mathrm{P} 2$. The two pumps were used to deliver flow streams in this system. PTFE tubing $(0.8 \mathrm{~mm}$ i.d.) was used to connect material in the flow system. Luminol (7.0 $\left.\times 10^{-6} \mathrm{~mol} \mathrm{~L}^{-1}\right)$, potassium ferricyanide $\left(4.0 \times 10^{-5} \mathrm{~mol} \mathrm{~L}^{-1}\right)$ and sodium hydroxide $\left(0.6 \mathrm{~mol} \mathrm{~L}^{-1}\right)$ entered the system respectively through the $\mathrm{b}, \mathrm{c}, \mathrm{d}$ pipes, meanwhile, mezlocillin sodium $\left(8.0 \times 10^{-6} \mathrm{~g} \mathrm{~mL}^{-1}\right)$ joined in system via a tubing. Mezlocillin sodium solution merged with the mixture of alkaline luminol $\left(0.10 \mathrm{~mol} \mathrm{~L}^{-1} \mathrm{NaOH}\right)$ and potassium ferricyanide and then reached the flow cell, increasing chemiluminescence intensity. The change of chemiluminescence signal in the flow cell was detected with IFFS-A multifunctional chemiluminescent detector. Data acquisition and treatment were performed with Sync Master T88DF software running under Windows 98. The concentration of mezlocillin sodium could be determined by the relative increased chemiluminescence intensity.

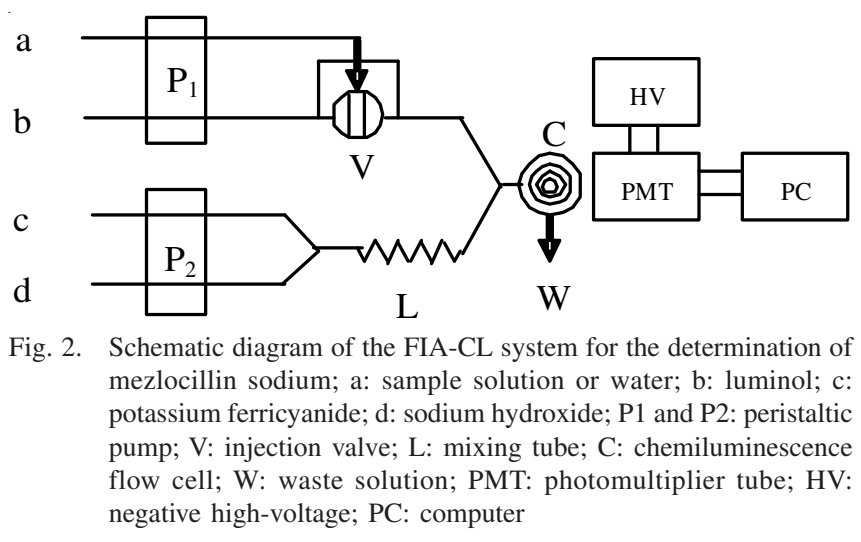

In order to obtain satisfied mechanical properties and stability, the instruments were run for $20 \mathrm{~min}$ before the first injection. Sampling rate was 20 times. $\mathrm{S}-1$ and sampling time was $10 \mathrm{~s}$. Pump speed was $30 \mathrm{r} / \mathrm{min}$ and negative high voltage was $650 \mathrm{~V}$. Three flow rates (mezlocillin sodium, luminol, potassium ferricyanide) were $1.82 \mathrm{~mL} / \mathrm{min}, 1.83 \mathrm{~mL} / \mathrm{min}, 1.77$ $\mathrm{mL} / \mathrm{min}$ respectively, while the largest signal-to-noise ratio was obtained.

\section{RESULTS AND DISCUSSION}

The order of mixing reactants: The mixing order of reactants has a great effect on the chemiluminescence intensity. Three mixing ways were studied: (luminol + mezlocillin sodium $)+($ sodium hydroxide + potassium ferricyanide $)$, (potassium ferricyanide + mezlocillin sodium $)+($ sodium hydroxide + luminol) and (sodium hydroxide + mezlocillin sodium $)+($ luminol + potassium ferricyanide). Results testified that the first way was the best one and high intensity and stable signals can be obtained.

Selection of the chemiluminescence system: Several chemiluminescence systems were investigated, such as potassium permanganate-formaldehyde, acidic potassium permanganateglyoxal, potassium permanganate-sodium sulfite, alkaline luminol-potassium ferricyanide, alkaline luminol-potassium permanganate, alkaline luminol-potassium periodate and alkaline luminol-hydrogen peroxide. The relative chemiluminescence intensity was very weak when potassium permanganate system was used. In the system of alkaline luminol, the relative chemiluminescence intensity was strong. Results indicated that the relative chemiluminescence intensity reached the maximum for alkaline luminol-potassium ferricyanide system. Thus, alkaline luminol-potassium ferricyanide system was chosen for further research.

Selection of the medium: The influence of medium (sodium hydroxide, sodium bicarbonate-sodium hydroxide and sodium carbonate-sodium bicarbonate) was examined. Results showed that the relative chemiluminescence intensity could achieve the maximum in sodium hydroxide medium. So sodium hydroxide was chosen in this work. The effect of sodium hydroxide concentration was studied over the range of 0.050-0.80 $\mathrm{mol} \mathrm{L}^{-1}$ as shown in Fig. 3. It was found that the signal was the largest at sodium hydroxide concentration of $0.60 \mathrm{~mol} \mathrm{~L}^{-1}$. The relative chemiluminescence intensity was stable. Therefore, the concentration of sodium hydroxide was chosen as $0.60 \mathrm{~mol} \mathrm{~L}^{-1}$.

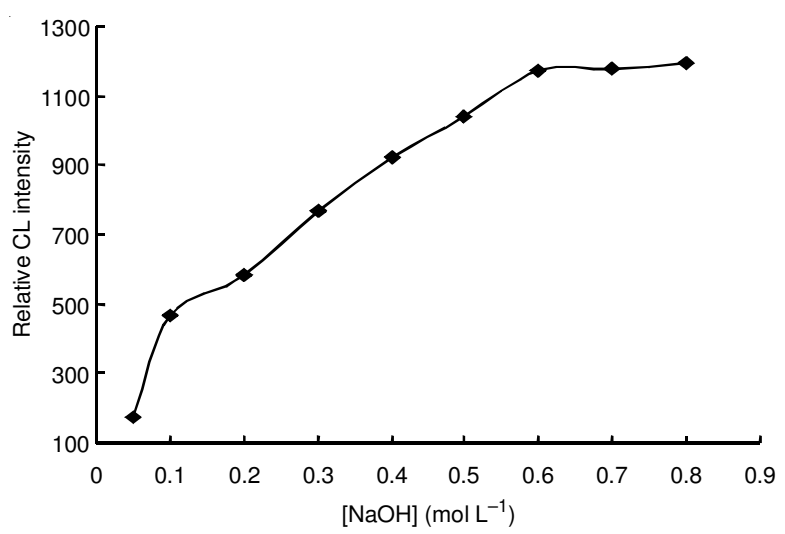

Fig. 3. Effect of sodium hydroxide concentration on the chemiluminescence intensity; potassium ferricyanide: $4.0 \times 10^{-5} \mathrm{~mol} \mathrm{~L}^{-1}$; luminal: $7.0 \times$ $10^{-6} \mathrm{~mol} \mathrm{~L}{ }^{-1}$; mezlocillin sodium: $8.0 \times 10^{-6} \mathrm{~g} \mathrm{~mL}^{-1}$ 
Effect of luminol concentration: Luminol was lightemitting reagent in this reaction, which not only affected the chemiluminescence intensity, but also affected the sensitivity and linear range. The effect of luminol concentration on the chemiluminescence intensity was investigated on the range of $5.0 \times 10^{-7}-1.0 \times 10^{-5} \mathrm{~mol} \mathrm{~L}^{-1}$ (Fig. 4). Results showed that the strongest relative chemiluminescence intensity was found at a concentration of $7 \times 10^{-6} \mathrm{~mol} \mathrm{~L}{ }^{-1}$. Thus, the concentration of luminol was selected as $7 \times 10^{-6} \mathrm{~mol} \mathrm{~L}^{-1}$ throughout the research.

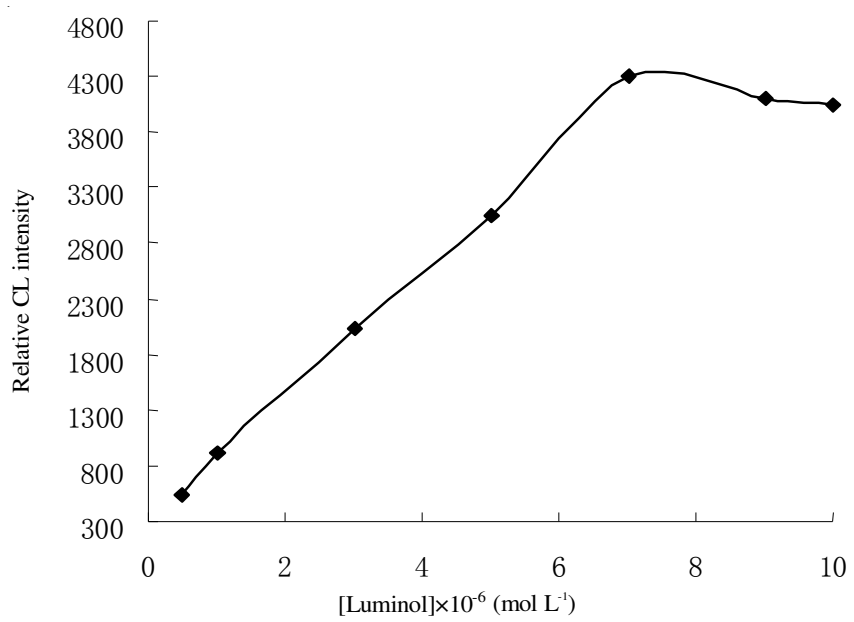

Fig. 4. Effect of luminol concentration on the chemiluminescence intensity. potassium ferricyanide: $4.0 \times 10^{-5} \mathrm{~mol} \mathrm{~L}^{-1}$; sodium hydroxide: 0.6 mol L ${ }^{-1}$; mezlocillin sodium: $8.0 \times 10^{-6} \mathrm{~g} \mathrm{~mL}^{-1}$

Effect of potassium ferricyanide: The concentration of potassium ferricyanide affected the chemiluminescence intensity and the linear range. The effect of potassium ferricyanide concentration was considered from $5 \times 10^{-6}$ to $1 \times 10^{-4}$ mol $\mathrm{L}^{-1}$ as shown in Fig. 5. Results demonstrated that the relative chemiluminescence intensity was on the decline at the concentration higher or lower than $4 \times 10^{-5} \mathrm{~mol} \mathrm{~L}^{-1}$. Consequently, the concentration of potassium ferricyanide for $4 \times$ $10^{-5} \mathrm{~mol} \mathrm{~L}^{-1}$ was chosen as optimum concentration for the following research work.

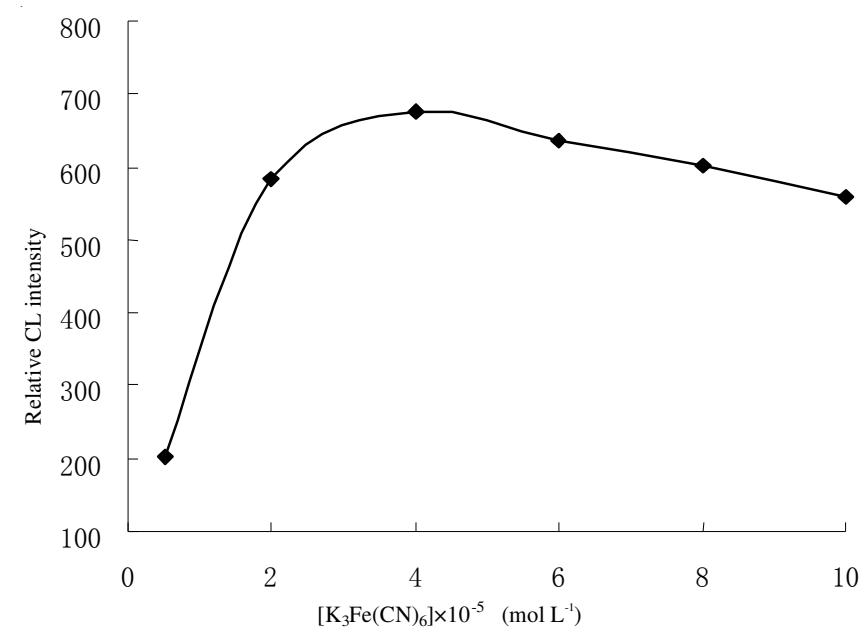

Fig. 5. Effect of $\mathrm{K}_{3}\left[\mathrm{Fe}(\mathrm{CN})_{6}\right]$ concentration on the chemiluminescence intensity. Luminal: $7.0 \times 10^{-6} \mathrm{~mol} \mathrm{~L}^{-1}$; sodium hydroxide: $0.6 \mathrm{~mol}$ $\mathrm{L}^{-1}$; mezlocillin sodium: $8.0 \times 10^{-6} \mathrm{~g} \mathrm{~mL}^{-1}$
Effect of other chemicals: The influence of surfactants and energy acceptors was investigated. The surfactants included sodium dodecyl benzene sulfonate, cetyltrimethyl ammonium bromide and Tween 80 . These surfactants $(1.0 \times$ $10^{-6}$ to $1.0 \times 10^{-4} \mathrm{~mol} \mathrm{~L}^{-1}$ ) had no significant enhancement on the chemiluminescence intensity. The energy acceptors, such as Rhodamine B, Rhodamine 6G and Fluorenone, did not increase the chemiluminescence intensity basically in the concentration range of $5 \times 10^{-6}$ to $5 \times 10^{-5} \mathrm{~mol} \mathrm{~L}^{-1}$.

Calibration curves and detection limit: Under the optimum conditions, the concentration of mezlocillin sodium with the relative chemiluminescence intensity was proportional in the range of $2 \times 10^{-7}$ to $5 \times 10^{-5} \mathrm{~g} \mathrm{~mL}^{-1}$. The regression equation was $\Delta \mathrm{I}_{\text {chemiluminescence }}=512.11 \times 10^{6} \mathrm{C}_{\text {mezlocillin sodium }}+$ $572.12, \mathrm{r}^{2}=0.9987$.

The relative standard deviation for eleven parallel measurements of $8 \times 10^{-6} \mathrm{~g} \mathrm{~mL}^{-1}$ mezlocillin sodium was 0.31 $\%$. According to the IUPAC recommendations, calculation with 3 times blank standard deviation, the limit of detection was $6.8 \times 10^{-9} \mathrm{~g} \mathrm{~mL}^{-1}$

Interference of coexisting substances: The influence of possible coexistence material on the determination of $8.0 \times$ $10^{-6} \mathrm{~mol} \mathrm{~L}^{-1}$ mezlocillin sodium was investigated. A 1000 -fold mass excess of excipients more than $8.0 \times 10^{-6} \mathrm{~mol} \mathrm{~L}^{-1}$ mezlocillin sodium was studied first. If interference occurred, the scale would be reduced gradually until the interference stopped. The criterion for interference was fixed at a $\pm 5.0 \%$ variation of the average relative chemiluminescence intensity calculated for the established level of mezlocillin sodium. No interference had been found when mixed in a 100 -fold $\mathrm{Na}^{+}$, $\mathrm{K}^{+}, \mathrm{Cl}^{-}, \mathrm{NH}_{4}^{+}$, 50-fold $\mathrm{Ca}^{2+}, 10$-fold $\mathrm{Fe}^{3+}, \mathrm{Br}^{-}, \mathrm{I}^{-}, 5$-fold $\mathrm{C}_{6} \mathrm{H}_{12} \mathrm{O}_{6}$, 3 -fold $\mathrm{C}_{6} \mathrm{H}_{5} \mathrm{O}_{7} \mathrm{Na}_{3}, \mathrm{HOC}\left(\mathrm{CH}_{2} \mathrm{COOH}\right)_{2} \mathrm{COOH}$ and the same concentration of $\mathrm{Cu}^{2+}, \mathrm{SO}_{4}{ }^{2-}$.

Determination of mezlocillin sodium for injection: Take five mezlocillin sodium for injection (each contains $1.0 \mathrm{~g}$ mezlocillin sodium), fetch its contents, weigh accurately and mix evenly. Then, $0.01 \mathrm{~g}$ of mezlocillin sodium was put into a beaker, dissolved with water and diluted to $50 \mathrm{~mL}$ ambercoloured measuring flask, shake uniform to prepare for the following use. Working solutions were diluted with water so that the concentration of mezlocillin sodium in the final solution was within the working range. The results of the determination of mezlocillin sodium for injection were shown in Table-1.

\begin{tabular}{cccccc}
\multicolumn{7}{c}{ TABLE-1 } \\
\multicolumn{7}{|c}{ RESULTS OF THE DETERMINATION OF MEZLOCILLIN } \\
SODIUM FOR INJECTION
\end{tabular}

\section{Conclusion}

In sodium hydroxide medium, mezlocillin sodium enhanced the chemiluminescence on the reaction of luminol 
with potassium ferricyanide. A flow-injection chemiluminescence method was proposed to determine mezlocillin sodium for injection with satisfactory results. This method did not require special reagents and offered advantages of simplicity, rapidity, high sensitivity and wide linear range.

\section{ACKNOWLEDGEMENTS}

The authors are indebted to the National Natural Science Foundation of China (No. 20905065), China Postdoctoral Science Foundation (20100471004), the Scientific Research Foundation for the Returned Overseas Chinese Scholars (State Education Ministry, [2009]1001) and the Natural Science Foundation of Henan Province (2008A180032, 2010A150024) for funding.

\section{REFERENCES}

1. H. Thadepalli and B. Rao, Antimicrob. Agents Chemother, 16, 605 (1979)

2. C. Odio, N. Threlkeld and M.L. Thomas, Antimicrob. Agents Chemother. 25, 556 (1984).

3. A. Dalhoff and S. Schubert, Infection, 37, 50 (2009).

4. S. Horster, L. Bader and U. Seybold, Infection, 37, 117 (2009).

5. G. Yetkin, B. Otlu and A. Cicek, Am. J. Infect. Cont., 34, 188 (2006).

6. R. Bromiker, I. Arad and O. Peleg, Infect. Cont. Hosp. Epidemiol., 22, 767 (2001)
7. M. Schwarz, R. Isenmann and E. Weikert, Infection, 29, 222 (2001).

8. E. Haen, J. Remien, E. Richter, U. Frank and D. Adam, Biopharm. Pharmacokinet., Eur. Congr., 2, 318 (1984).

9. J. Knoller, K.D. Bremm, W. Schoenfeld and W. Koenig, Antimicrob. Agents Chemother, 29, 527 (1986).

10. H.T. Karnes, L.A. Beightol and D. Farthing, Therap. Drug Monit., 9, 456 (1987)

11. G.L. Jungbluth, D.M. Janicke and W.J. Jusko, J. Chromatogr. B: Biomed. Sci. Appl., 494, 376 (1989).

12. S. Lam and E. Grushka, J. Liq. Chromatogr., 1, 33 (1978).

13. M.E. Rogers, M.W. Adlard, G. Saunders and G. Holt, J. Liq. Chromatogr, 6, 2019 (1983).

14. J. Haginaka, J. Wakai, H. Yasuda, T. Uno and T. Nakagawa, J. Chromatogr. B: Biomed. Sci. Appl., 341, 115 (1985).

15. J. Haginaka and J. Wakai, Analyst, 110, 1186 (1985).

16. J. Martin-Villacorta and R. Mendez, J. Liq. Chromatogr., 11, 1697 (1988).

17. X.D. Shao, X. Li and B. Liu, J. Anal. Chem., 64, 71 (2009).

18. W. Ruengsitagoon, S. Liawruangrath and A. Townshend, Talanta, 69, 976 (2006).

19. A. Waseem, L. Rishi, M. Yaqoob and A. Nabi, Anal. Sci., 25, 407 (2009).

20. Y. Huang and W.Liu, J. Pharm. Biomed. Anal., 38, 537 (2005).

21. H. Liu, L. Zhang, J. Zhou, Y. Hao, P. He and Y. Fang, Anal. Chim. Acta, 541, 12 (2005).

22. D.Y. Zhang, Y.J. Ma, M. Zhou, L. Li and H. Chen, Anal. Sci., 22, 183 (2006).

23. J. Ouyang, W. Baeyens, J. Delanghe, G. van der Weken and A.C. Calokerinos, Talanta, 46, 961 (1998).

24. B.J. Hindson and N.W. Barnett, Anal. Chim. Acta, 445, 1 (2001).

25. X.L. Wang, A.Y. Li and H.C. Zhao, J. Anal. Chem., 64, 75 (2009). 